\title{
Tesauro documental para la representación de contenidos educativos en videos
}

\author{
Catalina Naumis Peña \\ CentroUniversitariodeInvestigacionesBibliotecológicas \\ de la UNAM, 04510, MéxicoD.F., Tel: 56-23-03-29 \\ E-Mail:naumis@servidor.unam.mx
}

\section{RESUMEN}

Se presen ta el re sul ta do de una in ves tiga ción so bre mo de los de ela bo ra ción de tesauros, en la cual se obtuvo como producto un tesauro documental paralain te gra ción y sis te ma tiza ción temática de acervos au diovi sua les para la en se ñan za bá si ca, me dia y me dia su pe rior, así como colecciones culturales de nivel general. Un resultado colateral obtenido es la comprobación de que no existen tesauros educativos para contenidos curriculares. Por tanto reviste particular interés conocer la metodología para construir un lenguajecontrolado de tipo descrip tor, ba sa doen mapas con cep tuales del sis te ma edu ca tivo en el cual seráin serta do. Estelenguaje se dis tingue de otros por la ti pología do cu men tal que va a re pre sentar. Los do cu men tos que se rán ana li za dos y re pre sen ta dos con la he rra mienta cons trui da son vi deos que se trans mi ten por te le vi sión o a tra vés de una red de com pu ta do ras. Los vi deos han sido poco ana li za dos aún en elámbitobibliotecológico y su represen ta ción cons ti tu yeun temadeestudio para los sistemas de información.

Pa la bras Cla ve: Tesauros; Materiales Audiovisuales; Vocabularios Con tro la dos.

\section{THE DOCUMENTARY THESAURUS FOR REPRESENTATION OF EDUCATIONAL CONTENTS IN VIDEOS Catalina NaUmis-PeÑa}

\begin{abstract}
The pa per pres ents the re sults of re search on mod els for the sau rus elabora tion. The prod uct of the re search is a docu men tary the sau rus for in tegrating and thematically systematizing the audio-visual collections for basic, mid dle and middle- higher edu ca tion as well as cul tural collec tions in general. A collateral result is the verification of the non existence of educational thesaurus for cur ricular con tents. Thus it is highly per ti nent to know the meth od ol ogy for con struct ing a con trolled lan guage of a descriptor type, based on conceptual maps of the educational system in which it is go ing to be in serted. This lan guage dif fers from oth ers on account of the docu men tary ty pol ogy that is go ing to rep re sent. The docu ments which will be ana lyzed and rep re sented with this tool are vid eos to be trans mit ted byTV or through a com puter net work. Vid eos have been
\end{abstract}

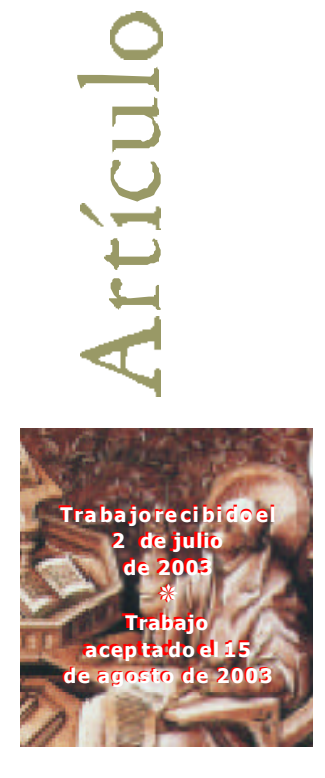


sel dom ana lyzed even in the li brary sci ence field and their rep re sen ta tion is a subject of study in information systems.

Key Words: Thesaurus; Audiovisual Materials; Controlled Vocabularies

\section{INTRODUCCIÓN}

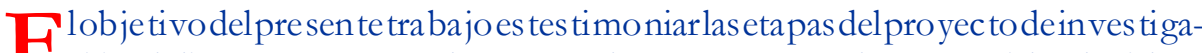
ción al diseñar un tesauro documental pararepresentarloscontenidos devideos analógicosodigitales, trans mitidos portele visiónomaneja dos enunaes ta ción multimedia, con el pro pó si to de be ne fi ciarla en señanza en los niveles de edu ca ción básica, mediabásicaymediasuperior. Estainves tigación seha desa rrolla docondosintenciones: de mos trar la utili dad teó ri ca de la pro pues ta de un mo de lo para cons truirunlenguajecon troladodedicadoalaindizaciónyrecuperación deun tipodedocumentosen unárea bas tan teinex plo ra da comolacons tituida porcon te nidoscu rricula resedu cativos de cualquier temática y que es impartida en los niveles especificados, y cumplir con el compromisoasumidoporelCen troUniversitariodeInvestigaciones Bibliotecológicas frentealanecesidadex presadaporlaDirección GeneraldeTelevisiónEducativa (DGTVE) y el Instituto Latinoamericano de la Comunicación Educativa (ILCE), de con tar con un tesau ro apli ca ble a los vi deos que se trans mi ten a tra vés de la Red Es colarde In formá tica Edu ca tiva (RedEs colar) y porla Red Sa teli tal de Tele visión Educativa (Edusat).

En elacuerdodecoopera ción, firma do porlas tresins titu cio nes, sees tableceque el ob je to del con venio es que elCUIB cons tru yaun tesau roque ayu de a lain te gra ción ysiste ma tización temática delosacervos au diovisualesdela DGTVE y el ILCE, para constituirla VideotecaNacionalEducativa, queserálares ponsabledelSistemaIntegral de In forma ción. Latele visión educa tiva en Méxi cosurge como unaalternativa paraproporcionareduca ción básicaala mayo ría dela población, peroposte riormenteseincorporala Telesecundaria, ${ }^{1}$ laSe cundaria dis tanciapara adul tos, la Ac tualiza ción y formación docente y otros programas tan importantes como los mencionados. ${ }^{2}$ En la actualidad la DGTVE y el ILCE emiten la señal de Edusat a treinta mil equiposreceptores en todo el te rri to rio mexica no, yal canza también aunam plio pú blicoenCa na dá,Estados Unidos, Centroy Suramérica. Además, secuen ta conseñal abier ta por ca ble en diver sos pun tos del país. ${ }^{3}$ La Red Edusattrans mitediariamente doce ca na les de te le visión de los cua les ocho cuen tan con progra ma ción pro piay diferenciadaycuatrosondeenlacedeseñal. ${ }^{4}$

\footnotetext{
Sara Espíritu Reyes e Irene MartínezZarandona (1999) p. 40

Sara Espíritu Reyes... op cit p. 44.

"Hitos y antecedentes de la televisión edu ca ti va y cul tu ral de Mé xi co (2003) p.9

Http://dgtve.sep.gob.mx/tve/red edusat/Tveducativa/en linea.htm
} 
México rea lizaun es fuerzo pordifun direl conocimien to ne ce sariopara ele varel ni vel de vida de la po bla ción y en la bús que da de lo grar ese ob je ti vo una de las ma yores preo cu pa cio nes es edu carparala supe ra ciónin dividualy, en conse cuencia, la colec tiva.La edu cacióny el pro gre so que sele aso cia ne ce sitan sis te mas eficien tes para organizarygaran tizarelacce so so cial delos conocimien tos dis po nibles enlosámbitosacadémicosytecnológicos.

Enlaactualidad, los me dios de acce so elec trónico al co no cimien to seacercanalos cen tros de do cen ciain virtien do cada vez más recur sos a fin delo grarun mayoral can ce para las grandes masas poblacionales. La Secretaría de Educación Pública mexicana está trabajando en la implantación de sistemas más modernos y poderosos para ampliarla ofertaedu cativay porello haim pulsadoel cre cimien to de las tele co mu nicaciones,loquesignificaunamayorpresenciaen todoslosámbitosgeográficosdelpaís.

La computadora conectada a través de Internet es un apoyo para el aprendizaje que seagrega al otrode los nuevos ex po nen tes de trans misión de conocimien to, la televisión que asícomo se utiliza para el en tre tenimien to transforman dolavidain dividual, familiar y social del hombre de nuestro siglo, se ha erigido en un modo de aprehensión de la realidad que lo rodea, "más allá del contenido específico de cada uno delos programas". 5 Los respon sables delas políticas deedu ca ciónen Méxicoreto maronlaopción dela tele visión ylain corpora ron comounimportantemedioedur cativo entre los años sesenta y setenta. ${ }^{6}$ En la actualidad los canales de transmisión edu ca tiva portele visión, a tra vés dela RedEdu sathanidoen au men toylaseñalllega, como ya se dijo, a otros países. Tan to la trans mi sión edu ca tiva a tra vés dela red como la televisión educativa trabajan en lo fundamental con programas de video previamenteproducidos; estos medios masivosdecomunicaciónleaportannuevasposibi lidades al entorno escolar y son esenciales en la educación abierta y a distancia. La simbio sis dela compu ta do rayla te le visión fa cilitará enlos años sub siguien tesla intercalación de documentosmultimedia, de tex to, de tex to con au dio, y deimá ge nes fijas o en movimiento con au dio o sin él, sin que el usua rio deba cam biar el apa ra to paraaccederalasdiferentespresentaciones deinformaciónparaelconocimiento.

La en tra da delain formación a tra vés delapro grama ción tele visiva,la comunica ción a tra vés de In terneto de una es ta ción de tra ba jo con el apo yo de vi deos edu ca tivos para la actualización docente, o el conocimiento o las imágenesquein te re sana alumnos, maestros y productores, abre un panorama alentador, pero no basta con disponer de motores de búsqueda poderosos con buenas capacidades y ayuda para

5 Joan Ferrés (1997) Vídeo y edu ca ción. p. 49.

6 "El fun da dordel sis tema de Tele secun da ria Mexicano, Carlos Fuen tes, des cribióla nueva forma deen señan za comola aper tu ra de una ven ta na al mun do para los niños delMéxico po bre. Éste era unideal que po dían sus cribir to dos los que tra baja ron parala tele visiónedu ca tiva en los mo men tos fuer tes delos se sen ta y seten ta. Millo nes y millo nes de dóla res sein vir tie ron en latele visióneduca tiva en todo el mun do, en la cre en cia de que se ha bía en con tra do una res pues ta a las ne cesidades edu ca ti vas del mun do."John Tiffin y La li ta Ra ja sing ham (1997) En bus ca de la cla se vir tual: la edu cación en la sociedad de la información. p. 122. 
buscar la información contenida en ellos, se requiere de instrumentos destinados a sis te ma tizarlain for ma ción a fin de evitarunare cupe ra ción demasiadoex haus tivay pocopertinenteolaausenciadeinformación.

Eldiseñodelos videos edu cativos y su calidadin trínseca es tan importan te como suin tegraciónaun siste ma dein formación eficien tequerepresentesucontenidoylo haga circular. Unproduc to excelentequeno se difunda a tra vés deunaorganización adecuada esinú tilenlasociedad dehoy en día.

Porestarazónlosvideos educativos deben representarseyclasificarse enunregis tro catalográfico completo en los temas que contienen, para asegurar su recuperación, difusiónyuso. Enestecon tex to, al ma cenar, regis trar, cla sificary re sumires una ope ración cos to sa, perolos vi deos tam biénlo sony la de sin for ma ción tiene el cos to agregadodesuposibledesaprovechamiento.

\section{DESCRIPCIÓNDECONTENIDOSEDUCATIVOSMULTIMEDIA}

Ladescripción de contenido tieneporobjetivopre cisarel campode conocimiento; cla si ficarlos di fe ren tes te mas quelo componen; ex pre sarés tos en términosconcre tosy sinambigüe da des, ytra du cirdichos tér minos alas ex presiones más apro pia das de un lenguaje documental apropiado al sistema de información en el cual será insertado para formar conjuntos de documentos. ${ }^{7}$ En la descripción de contenido estáim plíci ta en tre otras co sas la agru pa ción de acuer do con una cla si fica ción. "Cla sificar,entérminosgenerales, es elactodeorganizareluniversodelconocimien to en algún orden sistemático. Ha sido considerada la actividad más fundamental de la men tehumana. Elacto de clasi ficarcon sis te en el dico tó mico proce sode dis tin guir co sasu obje tos que po seen cierta caracte rís tica de aquellos que no la tie nen, yagrupar enunaclasecosasuobjetosquetienenlapropiedadocaracterísticaencomún". 8

Laclasificación de la informa ción se rea liza a tra vés de sis temas: nu méricos, al fabéticos, alfanuméricos, fa ce ta dos o te máticos, que sirven para dis tribuir los documentos que conforman una colección, base de datos o sistema de información agru pán dolos de acuer do con la cla sifica ción es cogida para ello, des pués de so meterlos al procesodeindiza ción. En oca sio nes se cons tru yen clasi fica cio nes delcono cimien to, otras sólo se aplican es que mas de cla si fica ción ya es truc tu ra dos an teriormente. La aplicación de esquemas de clasificación bibliográfica, numéricos o alfanuméricos para la ubicación física del documento(signatura topográfica) con res pec to a otros en una co lec ción, obliga a re co ger sóloun as pec to de los múl ti ples quepue decon te nerundocumen to, lo que sig ni fica que se debe es cogersu con tenido central. Los registros bibliográficos deben exhibir además otra clasificación

7 Catalina Naumis Peña(2003) "Indizaciónyclasificación:unproblemaconceptualyterminológico"

8 Ci ta do por Blan ca Gil Ur di ciaín. Manualdelenguajesdocumentales. - p.67 — Fuen te pri ma ria: L. M. Chan. Catalogingandclassification: an introduction. New York: McGraw-Hill, 1981, p. 209 
temática para re coger en pala bras los términosquerepresen ten to doslos te mas que contieneundocumento.

Colocadoenlaes tan tería de unabiblio te caelvideoesundocumen todenatu ra leza diferente al libro, en un video pueden incluirse varios temas sobre muy diversas áreas del co no cimiento, por locual su or de na ción en es tante rías sólopue de ha cerse me dian te un orden nu mé rico pro gre sivo o por lu gar de pro ce den cia, al igual que en los ar chivos, yes laclasi fica ción te má tica desu con te ni doloque per mi ti rá elaccesoa lain formaciónque con tiene. En una video te ca digitalizada elorden temá tico seráel preferido para recuperar los contenidos; de ahí la importancia que se le otorga a un sistema de información que permita organizar los videos de acuerdo con los temas quecontieneparalocalizarlosconrapidez.

La clasificación temática se representa a través de términos normalizadosque se estructu ranenunlenguajedebús que dayrecuperacióndeinformacióndocumental de tipodes crip tor, que funcionan in te gra dos en un tesau ro y do tana esos términos de características propias adecuadas a las necesidades del sistema de información del que forman parte. Para una recuperación más integral los descriptores del tesauro do cu men tal se rán al terna dos en la base de da tos con pa la bras cla ves so bre el títuloo losresúmenes delos regis trosincluidosen elsistemayconidentifica do res delugares, espacios y personajes. Los identificadores son lis tas deau to rida desque ase gu ran el mismousoparadescribirelmismocontenido.

Las palabrasclaves ex traídas en formaau to máticanocompitenconlainformación indizada por medio de descriptores extraídos de un tesauro documental, sino que le otorgan ma yor pre ci sión al sis te ma para la re cu pe ra ción, por que nos guía de los tér mi nos de in di za ción no usa dos en ésta ha cia los des crip to res; es de cir alos térmi nos normalizados y validados para la indización, además de recoger todas las temáticas que pue dacontenerundocumento, aun queno hayansidoexpresadas a tra vés detérminos quelasidentifiquen. Untesau rodocumentalse definecomo: una es tructuralingüística declasificacióntemáticaofacetada, cuyaorganizaciónbásicaestáconformadaporuna relacióndedescriptoresquerepresentanodescribenau toridadesocontenidossemánticos, ex traídos dellenguaje for malde una dis ciplinaoárea es pe cífica del conocimiento. ${ }^{9}$ Sedesta can enlain te gra ción del tesau rolos des crip to res que an tes de su normaliza ción para elsis te ma dein for ma ción sonvalida dos por la co mu ni dad de origena través dela "garantíaliteraria", es de cirsuuso en documentoselaboradosporau to res dep restigioquerecogenlaterminologíadelaespecialidad.

En un sis te ma de in forma ción mul ti me dia ala vezque se con tem plan los cam pos requeridosparala descrip ción de formaylos des tinados alosidentificadores de personajes, ins tituciones olugares geo gráficos, sedes tinaunoparalos descrip tores dela clasificación temática con la finalidad de obtener la recuperación precisa de la informaciónvideográfica. Para ob te nerun re sul ta do eficien te en la ope ra ción declasificación

9 Ca talina Nau mis Peña (2000) “Análisis dela con fluen cia en tre tér mi no y des crip tor en la ela bo ración de tesau ros" 
te má tica es necesariocon tarcon el tesau rodocu men tal para norma lizarla in forma ciónquecontieneelcampodes tina doa ellayotorgarleasícoherenciaalaindización.

\section{TESAUROS EDUCATIVOS}

Laprimera al ternativacuan dose em pren diólaca talogación devideos delared de Televisión Educativa fue la búsqueda de tesauros ya estructurados para aplicarlos o adaptarlos al nuevo sis te ma de in for ma ción para do cu men tos au dio visua les. Se comenzó entonces una minuciosa revisión bibliográfica y se obtuvieron varios tesauros en el dominio de la educación que se revisarontanto en español como en otros idio mas, peroningunode ellos res pon día ala es truc tura delos contenidoscu rricula resedu cativos ola organización que presen ta ban era de ma sia do po bre para res ponder a un sistema de enseñanza, y tam poco se clasi fica ban as pec tos de di fu sión dela cul turaparagran des masas, ob je tivos delaimplantación del sistema dein formación paramultimediaeducativa.

Surgió asíla ne ce si dad de ela bo rarun tesau ro que res pon die ra a los siguien tes objetivos básicos: 1) servirdevoca bula riooficial paraindizarlos videosingre sa dos en un sistema de información para multimedia educativa y recuperar información en ellos para los maes tros de edu ca ción bá si ca, me dia y me dia su pe rior, alum nos y productores;2) lograrunanormaliza ción delaterminología del sistemaeduca tivomexicano que tome en cuenta los ma pas de con te nidos educa tivos;3) proponerunconjuntoes tructuradodetérminossobrelabase deun siste madeconceptosaptosparala orga niza ción de contenidos edu ca tivos;4) con tex tua li zarcadaunodelos descriptoresin cluidosatravés derela ciones semán ticasen el marcode suespecialidad;5)clasificarcadauna delas temáticas aborda das en el sis temaeduca tivomexicanodentrode losnivelesbásico,mediobásicoymediosuperior.

Lanormalización dellen guaje formal deunabase de da tos que ex presa términos en una mis malen gua, perocon va ria ciones en ex pre siones para no mi narlosmis mosconceptos, allana elcamino ycrea con dicionesobjetivasfavorablesparala trans ferencia de in forma ción. Lacrea ción de lenguajes debús que day re cupera ción dein forma ciónen castellanoconstituye una aporta ción parauna regióngeográ fica bas tan teamplia, porque aunque el tesauro refleja el sistema educativo mexicano es útil (haciendo adaptaciones),paraotrospaíses delenguaespañola.

Lapla nifica cióndel tesau ro esuna etapaimportante porquesu diseñoes unatarea comple jayrequie re delapo yo derecursos humanosenvarias dis ciplinas, acervos documentalesespecializados, buensustentoinformático, fondoseconómicossuficientesylaprogramacióndetiempos. 


\section{DOCUMENTOAUDIOVISUAL EDUCATIVO}

Enlaac tualidad elvideo pugna por hallarsuiden tidad es pe cíficacomo medio expresivoportadordeinformación-conocimiento que puedeintegrarse en el proceso educa tivocomootravaliosa fuente dein forma ción. Lasposibilidadeseducativasde este so porte se poten cian gra cias a la versatilidad del me dio: se pue de de tenerlaimagen, se pue de bus car la ima gen más cerca na ala in for ma ción prio ri ta ria que se quie re trans mi tir, y se pue de ami no rar o ace le rar el paso de las imá ge nes. Elvi deo como ele men to di dác ticoesim portan te porejemplo “[...]cuandoel fe nó me no quehayquees tudiar in clu ye el movi mien to, como es el caso del es tu dio del co ra zón como bomba impul soradelasan gre. Ocuan donobas tala ex posiciónverbalparasu perfectacomprensión, mejorando al ser visualizada, como es el caso de la observación celular al micros copio elec tró nico. Ocuan do por su es pe cialaridezen cuentre en el me dio aur diovisual un elemento mo tiva dor. O cuan dolain te gra ción dela ima gen y el so ni do favorezcalacomprensiónymemorizacióndeloscontenidos."10

Elmaes trodebecontarconme diosquelepermitanseleccionarlosprogramas de vi deo ya elaborados para cum plircon los obje tivos delas en se ñan zas que ha pla nea do. Esta nueva nece si dad es tam bién un reto para los orga nizado res dein formación porquelana tu raleza de es tos documen tos, a di ferencia de ma te riales di dác ticoscomolos libros, exigesulectura conapara toslectores adecuados. Además, se puedeperderlainformacióncongranfacilidadytales documentossedeterioranconeluso frecuente.

La experiencia bibliotecológica es amplia en el procesamiento de documentos textuales, no así con los materiales audiovisuales porque la comunicación audiovisual y su transmisión a través de un lenguaje documental implican un dominio del lenguajeaudiovisualparatransmitirlo.

Rodríguez Bravo define el lenguaje audiovisual como “[...]los modos artificiales de orga niza ción delaimagen y el so nido que utiliza mos para trans mitirideas o sensa ciones, ajustándonosalacapacidaddelhombreparapercibirlasycomprenderlas". ${ }^{11}$

Se estudia el lenguaje audiovisual como un subconjunto del lenguaje natural, para trans mitirin formación muy similaralain formación na tu ralpero quenoesla misma; es decir,ellenguaje au diovisual seutiliza para trans mitirin forma ción simula da de forma artificial acerca del entorno natural del hombre. El lenguaje audiovisual usa distintas técnicas deimita ción, demane ra fide digna ono, so brela mismarealidad, rehaciéndola parapresentarlaenformaclarayadecuada paraunusuariopredeterminado.Rodríguez Bravodestacalacapacidaddellenguajeaudiovisualparavehicularnarracionesmediante mensajesdirigidossimultáneamente a va rios sen ti dos, de modo que se per ciban de formamuysimilaracómosonpercibidoslosfenómenosnaturales. ${ }^{12}$

Elescena rioactualparalascla sificacionestemáticasrepresentadaspordescriptores se ha diversificado.Los medios que trans miten el co no ci mien to son, ade más de

10 Ibidem p. 92.

11 Ángel Rodríguez Bravo (1998) Ladimensiónsonoradellenguajeaudiovisual. p. 25

12 Ibidem p. 28. 
es critos en pa pel, audio visuales, imageno au diodigitales yen es tos dis tin guimosdigitales originales o digitales de destino. "Enel al macena mien to deseñales dis tinguimos en trelos so por tes rela tivos al fe nó meno mag nético, los de fe nó me no óp tico y losde desviaciónmecánica, queesladerivacióndeun surcosobreunasuperficie.Los soportesmagnéticosyópticosseusan paralasseñalesanalógicasydigitales, mientras que en la prác tica los so por tes me cáni cos, en su forma de cilin dros o dis cos, han sido usados solamente para señales analógicas, y los discos magnético ópticos han sido usados solamente para grabaciones digitales, moldes o matrices metálicas para la producción de soportes mecánicos, así como de discos compactos y discos digitales". ${ }^{13}$ Ade más de la in forma ción en so por te ma te rial manipula ble se dis pone de informaciónqueseobtieneyconsultaatravés delastelecomunicaciones.

La indización no refleja la diversidad mencionada de soportes y señales, porque parte dela ex trac ción de sus sig ni fica dos para rela cio narlos con las in ter pre ta ciones queunusuario pue da hacerso bre esos signi fica dos.Sinembargola na tu ralezadeldocumen to au diovisual exhibecaracterís ticas propias de bido al he cho de quela co mu nicaciónaudiovisual modifica la percepción ori gi nal del ser hu ma no por otras creadas y desarrolladas en forma artificial,portantolarepresentacióndocumentaltambiénreflejaesaspeculiaridades.

Ladi ficul tad del proble ma es eviden tedes de elmomen toen que el me dio au diovi sual tra ta de re pro du cirla rea li dad. Para orga nizarun sis te madein for ma ción los documentos audiovisualesdeben ser represen ta dos des de el pun to de vis ta del tema o acontecimientotratado a lo lar go del do cu men to, al igual que en los sis te mas de informaciónimpresatradicional,peroademás debenrepresentarobjetosmuy pun tua les, aun que la apa ri ción sea fu gaz, (como en el caso de per so najes, ins ti tu cio nes o información muy específica) y esté ligada o no con el tema general del documento digital original o principal. En un sistema de información digital la presencia de los des crip to res quela re pre sen tan es sin duda más abundan te en can ti dad que en los sistemasimpresostradicionales(Burke,1999,96).

Eles pecta dorde unaimagen (en al gu nos as pectos en forma similarallec tordeun texto escrito) tiene un conocimientopropio además del conocimientoque le transmite el au dio vi sual, y un sa ber que se re fle ja en la in ter pre ta ción que hace de ese audiovisual. Pero ade más el es pec ta dor es un su je to con emo cio nes que tambiénin fluyenensupercepcióndelaimagen.

Para trans mitirel con teni do de un au diovisual ha brá queoptaren trelagama de sa beres, conocimientos, percepciones, sensaciones y emociones que éstos pueden provocar en eles pec ta dor.Sise tra ta de orga nizarlain forma ción que con tie ne unaudio visual para fines edu ca tivos, la op ción pa receun pocomás cla ra que cuan dose tra ta de audiovisualesde entretenimiento. Sin pretender ahondar en las diferenciasde los tipos de audiovisuales, cabe aclarar que en el audiovisualeducativolasimágenes

13 Normas,prácticasrecomendadas y estrategias IASA-TC 03 (2001) - p. 5 
de ben sermuyprecisas, porqueideal men te el alum no debere cibir el men saje que se lequieretransmitir.

Paraindizarlaimagenen movimientosepartedeex trapolarlainformaciónaudiovisual con baseen la pro pues ta de Pa nof sky para cla si ficarobras de arte porel asun to, el significado,ola forma:descripción preiconográ fica,iconográficaeiconológica. ${ }^{14}$ El significado primario o natural, que se subdivide en fáctico y expresivo, es el que se aprehendeidentificandolas formas puras, estoes, determina das configu racionesde línea y color, o de termi na das ma sas dema de ra o piedra de for mas peculia res, como representaciones de objetos naturales, por ejemplo seres humanos, animales, plantas, casas, he rramientas, etcéte ra. La trans mi sión de significa dos a tra vés dela forma cons ti tu ye una des crip ción "prei co no grá fica" dela obrade arte. Cuan do se hablade "asunto en oposición a laforma" la re fe ren cia es a la es fe ra del asun to se cun da rio o convencional, estoes, al mundo de te maso con cep toses pe cíficos que semani fies tan en imáge nes, na rracio nes y ale go rías, en opo si ción ala es fe ra delasun to prima rio onatural, que se manifiesta en objetos. La identificación de tales imágenes, narraciones y alegorías cons ti tuyeeldominio deloquecorrientementesede signa con el nombre de "iconografía".

El significadointrínsecoocontenidose re cono ceporlos principios sub ya cen tes que ma ni fies tanunaac ti tud omodode vida con den sa do enuna obra. Es tos prin ci pios se revelan me dian telosméto dos de composiciónasícomo a través delasignificacióniconográfica.Se con cibenlas for mas puras, los mo tivos, lasimáge nes, las na rra cio nes y alego rías comomanifesta ciones deprincipios subyacentes, ysein terpretantodosestos ele men tos comosimbólicos. Eldescubrimien to ylain terpretacióndees tosvalores sim bólicos (que a me nu do son des co no cidos porquien pro du ce la obray has ta pue de dife rirdelo que se propu sie ron ex presar) es ob je to de lo que Pa nof sky deno mina "iconología". 15

En cualquier narración audiovisual el instrumento expresivo fundamental y que ubicalaimageneselcontenidosemán ticoexpresadoatravés delalengua escrita o habla da. Las es tructuras lin güís ticas no sóloubi canla imagen, sino que con tex tualizan la significación del documento audiovisual en su conjunto. Rodríguez Bravo al respectodice: “[...]elcon tenidolingüís tico es el que proporcio na al recep torla re fe rencia de cómo ha de serpercibido todo aquello que es ta mos viendo yoyendo, conobjetodequeladescodificación novayaala deriva." 16

Lautilización didáctica delau diovisualserealizaapartirdecontenidoseduca tivos previamentede finidos,poresarazónunlenguajedocumentalconstruidocontérmi nosnormalizadosdellenguaje formaldela disciplinaque se persigue en se ñar, representa elcon tenidoilus tradodelos programas educativos transmitidos enformatoaut diovisual.Losdocumentosaudiovisualeseducativoscontienenvoces que expre san en

14 Erwun Panofsky (1970) El significado en las Artes Visuales. - p. 39.

15 CatalinaNaumis Peña (2002) "Images and words". - p. 122.

16 Op cit p. 263. 
lenguaje habla do el con teni do semán tico que trans mi ten y que pue de sertradu cidoa un lenguaje do cu mental.Dice Rodríguez Bravo "El tex to oral es ca paz de es tructu rar tan to la vi sión comola au di ción, y sus con te nidos suelen serlos que de terminan, enúl timainstancia, cuáles el tipodedescodificaciónquevanahacernues trossentidos". ${ }^{17}$

Porlo tan to para re presen tarelcontenidodelos videoses válido utilizarun tesau ro in tegradoporlos conceptos contenidosenel propio sis temaeducativo; deesta manera seinten ta fijarla rela ción en treel objeto dela realidad, el concep toy laimagen que lo representautilizandoloselementosquelebrindalabibliotecologíaylaterminología.

\section{METODOLOGÍAY MÉTODOS}

Tanto Lancaster como Aitchison y Gilchrist proponen utilizar cualquiera de los dos méto dos siguien tes paracons truirtesau ros: eldeduc tivoy elinduc tivo; los au torescoincidenentérminosgeneralesenlainterpretacióndeestosmétodos. ${ }^{18}$

* El método deductivo im plica con fre cuen ciala participa ción de co mi tés en su elaboración.

* Elmétodoin duc tivo o empíricoutiliza los méto dos dela terminología para recolectar los términos y construir el corpus de los vocabularios.

El tra bajo a par tirdel méto do de duc ti vo co mien za porcons truirel mapacon ceptualdel cam po del cono cimien to im plicado:se parte delos te mas prin cipales en que se sub divide una dis ciplina y a su vezés tos se sub di viden en ca te go rías. Es una ta rea difícil porque no conoce mos con certezalos tipos de je rar quías que re quie renlos sistemas, auncuando sehayahechoun es tudioprofundodelosdes tinatarios. Elcomité debees tarin tegradoporespecialis tas delcampoinvolucrado, lingüis tas yespecialistaseninformación.

Los especialistas de la temática deberán aportar su conocimiento para elaborar el mapa conceptual; los lingüistas especializados en terminología asesorarán la calificación de los descriptores que deberán incluirse, desde el pun to de vis ta sin tác tico ysemántico;ylosespecialis tas enin formaciónorganizaránlaestructuradel tesauroy aportaránlos puntosdevistadelosindizadoresyusuariosdelsistemadeinformación.

Elméto doinductivooem píricopara cons truirel tesauroes el ex tre moopuestoyes muchomás se gu ro.Los términos en con tra dosen elcampodein te rés sereúnenapartir de va rias fuen tes y las ca te go rías o jerarquías de términos sevan for man do a tra vés del uso. Hul meen 1911, propuso partirdelaga ran tíalitera ria odela au to ridadbibliográficapara elaborarloses que mas de una cla sificación bibliográ fica; deestemodo,lasjerarquíasseríancons truidas de acuerdoconloscontenidosdelaspublicaciones. ${ }^{19}$

17 Op cit p. 264.

18 - F. W. Lancaster (1985). Thesaurus cons truc tion and use a con den sed cour se. - p. 10.

- Jean Aitchison y Alan Gilchrist (1987). Thesau rus cons truc tion: a prac ti cal ma nual. - p. 121.

19 F. W. Lan cas ter (2002) Elcon troldelvo cabula rio en la recuperación de información. - p. 43. 
En general los úl ti mos au to res quehan tra ta do el tema coin ci den en pro po nerla utiliza ciónde los dos méto dos para cons truirel tesau ro. Esto lo re su me muy bien Gil Urdiciain ${ }^{20 "[. . .]}$ exis tela po sibilidad decombinarambos proce dimien tosen el mé tododerecopilación mix to, quesumalas ven tajas delos proce dimientos analíticoysintéticoypermiteasegurarlacreacióndeunasolabasemetodológica". ${ }^{21}$

Enlaplanificacióndeltesau ro serealizóunes tu diodetalladoparapre cisarlade finición de objetivos, el tipo de usuarios consultores y el tipo de tesauro que habría de cons truirse. Asítam bién se di fun dióla de ci sión de cons truirel tesau ro paracon tarcon el auxilio de otros especialistas que hubieran tenido experiencias relacionadas con el proyectoyparaasegurar,unavezmás, lainexistenciadetrabajosparalelos. ${ }^{22}$

Enmateriacom pu tacionalse analiza ronvarios programas ofrecidos enelmerca do, para cons truir el tesau ro. Un soft ware que sirva para este pro pó si to debeofre cer lossiguientesservicios:

* permitir el almacenamiento y consulta de por lo menos 20.000 términos

* conformar un nivel de profundidad en las categorías de por lo menos 20 niveles

* poderrevisarlas equivalencias desinónimos,ylasrelaciones semánticasy jerárquicas

* poder confeccionar los índices

* transformar la información en lenguaje HTML

* contar con actualizaciónyapoyotécnico parasertransferidoposteriormente a una base de datos, y poder proporcionar información sobre su utilización

Para de sarrollarla he rra mien ta lingüís tica se tomóen cuen ta el programacompur tacional Thesaurus Construction System Liu-Palmer, que ofrecía la mayoría de los servicios mencionados y una revisión de las relaciones adecuadas. El sistema fue construido por una asociación de bibliotecólogos norteamericanos retirados, con granexperienciaeneltema,perofuedescontinuado.

Encuan toala organización del tesau ro seelabo ró un proyec to en elquese presenta ronlosobjetivosylametodologíadetrabajo,además deincluirlaestructu ra conceptual del tesau ro enlas sie teáreas que reconocela edu caciónen México y deseguirelSis tema Edu ca tivo de laSe cre taria de Edu cación Pública fija do en el Mapa de Con te ni dos estructurado para los tres niveles educativos y construido por la Dirección General de TelevisiónEducativa.Lavalidezdeladivisión parasus tentarla organizacióndeltesauro pro viene del "[...]prin ci pio de res pe to dela es truc tu ra, se gún el cual un fon do dea rchivo debe conservar o recibir una clasificación correspondiente a las estructuras

20 Blan ca Gil Ur di ciain (1996). Ma nual de len gua jes do cu men ta les. - p. 207

21 Ibid.p. 207-

22 ElCentroUniversitariodeInvestigaciones Bibliotecológicas acordóeldesarrollo del tesau ro con la par ti ci pa ción de las ins ti tu cio nes que se ocu pan de la pro duc ción y or ga ni za ción de los vi deos: Dirección GeneraldeTelevisiónEdu ca tiva dela Secretaría deEdu ca ción Públicayel Ins titu to La tinoamericanodelaComunicaciónEducativa (laVideotecaNacionalEducativasur ge con pos terioridad, como una estructura insterinstitucional para distribuir la producciónvideográfica). 
administrativas in ter nas delorga nis mo que lo ha crea do". ${ }^{23}$ El Mapa de Contenidos sólo contiene los nombres de las asignaturas, y la mayoría de éstas son genéricas, sin embargobrindalagransegmentacióndelosconocimientoseducativosimpartidosque seexponenacontinuación:

* CIENCIAS NATURALES

* CIENCIAS SOCIALES

* LENGUAJE Y COMUNICACIÓN

* ingENIERÍA y TECNOLOGÍa

* MATEMÁTICAS

* EDUCACIÓN FÍsICA

* EXPRESIÓN ARTÍSTICA

Parasu cons truc ción se cons ti tu yóun co mi té de diezes pe cialis tas, cadauno delos cua les tenía ex pe rien cia en edu ca ción en elárea asigna da, o bibliote cólogos tam bién conconocimientos dela mate ria co rres pon dien teo expe rienciaenalgúnins trumentolingüís ticoparain dizary re cuperarin formación. Elequipo in clu yóade más unlingüis taysuayu dante, un especialistaencóm putore forza doposteriormenteconlaincorpora ción deunayu dante, yunadminis tra dordel proyecto, aglutinados to dos por la coordinación de una investigadora con experiencia en construcción e investigacióndetesau rosyanálisisysis tematizacióndeinformacióndocumental.

Parauni ficarcrite riosy conocimien tos seim partie ron cursosalgru podel tesau ro conla participa ción ac tivadelosequipos, tan to de cons trucción del tesau rocomode su uso posterior para la indización en el ILCE, la DGTVE y la Videoteca Nacional Educativa.

La cons truc ción de un tesau ro re quie re el em pleo de mé to dos en los que prevalezca un alto grado de validación empírica de todos y cada uno de los ele men tos quelo componen, de bi do a que su es truc tu ray apa ra to terminológicoconstantementeestánsiendosometidosapruebasdeeficiencia mediante la práctica y la sistematización de la búsqueda y recuperación de información. ${ }^{24}$

Larevisión delis ta dos de términosutiliza dos parain dizarbases de da tos ya existentespermi tiónor malizarun primerlis ta do aplican do algunasnor mas de valida ciónyla incorporación de los términos candidatos considerados básicos o que eran complemen ta rios de algo que se percibía como una cla se; por ejemplo, siapa re cía el nombrede una raza de pe rro se complemen ta ba con las otras ra zas co nocidas en México, es de cir elmétodo consistió enin tegrararmónica, coherente,limita day fundamentalmentelos diferentestérminospresentesenlosvocabulariosquesirvierondebase.

Unavez con cluido el lis ta do normalizado base, se realizóunes tudio sobrelaconveniencia de es truc tu rar las ca te go rías del tesau ro en fa ce tas o en ma pas con cep tuales. A continuación se explica brevemente el análisis realizado para organizar cada

23 José Martínez de Sou sa (1993) Diccionario de bibliologíaycienciasafines. p. 158

24 C.Nau mis yM.T. Igle sias (1999) "Unlenguajeparala orga nización del co no cimien to biblio te cológico en América Latina”, p. 81. 
uno de estos tipos de catego rías con lain ten ción de es truc tu rar el tesau ro. Para precisarlosconcep tosquesevanautilizarsedefinecatego ría como:

[...]abstracciones simplificadas que, con fuerza de herramientas intelectuales, sonusadas porlos clasificacionis tas paraindagarlas regularidades de los ob je tos del mun do físi co y del ideal y de las no cio nes que los representan, conelobjetodeorganizarlógicamentesistemasdeconceptosaptos para la organización del conocimiento en general, y la clasificación documental en particular. ${ }^{25}$

Seusan ca te go ríascuan do se re fie re auna es tructu ra deco noci mien to queva delo generalaloparticular, yface tas cuandose trata de una manifestacióndelasca te gorías principales en tipos de agrupaciones válidas para diferentes categorías principales . Una estructura facetada puede comenzar con una primera división en categorías prin ci pa les en las que se sub di vi de la dis ci plina que re presen ta el tesau ro, y cada uno de es tos te mas principales es sub dividido en face tas de acuerdoconla na tu ralezade las sub divisiones a las que se pue de so meterun con cep to. Una face ta con sis te en un grupo de términos que representan una, y solamente una, característica de división deuncampotemático.

Cada unodelostérminos que representanuna ca rac te rís ticade división, se constitu ye a su vez en la subfa ce ta que usa su pro pia ca rac te rís tica de di vi sión. Cada una de estas face tas y subfacetas re presen ta una ca rac te rís tica de división que no seencuentra en nin gu na otra fa ce ta o subface ta. Es de cir, dos fa ce tas o subfa ce tas no pue den contenertérminosquerepresentenelmismoconcepto. ${ }^{26}$

Ranganathan propone una segmentación del conocimiento sobre una tabla de mate rias principales, alas cuales subdivide en cincoca rac terís ticasde división: PERSONALIDAD,MATERIA, ENER GÍA,ESPACIOYTIEMPO. Estas mismas divisionessonutilizadasparalassubsecuentessubfacetas.

Con la siguien te cita se re su me con ejem plos el uso de las fa ce tas que hace Ran ganathan. "Así para la ASTRONOMÍA la PERSONALIDAD será la tie rra, la luna, el sol, las es tre llas y otros... laMATERIA de laMONEDA será el oro, la pla ta, el co bre... La ENERGÍA ...en MECÁNICA será el mo vimien to, el equilibrio, la vi bra ción... ElESPACIO ... suponelalocalización espacialein cluyela división te rrito rialconvencional... ElTIEMPOesválidoparalalocalizacióntemporal...”27

La es truc tu ra en ma pas con cep tua les se basa en la pro pia es truc tu ra de la dis cipli na para la cual se ela bo ra el tesau ro. La es truc tu ra con cep tual es un len guaje usa do para representar una clase de entidades mentales denominadas conceptos... ${ }^{28}$ Laidea de con cep to que se ma neja en bi blio te co lo gía toma su sus ten to en la Teo ría

25 Ma rio Gui do Ba ri te Ro que ta, (1999) "La no ción de ca te go ría y sus im pli ca cio nes en la cons trucción y evaluación de lenguajes do cumen tales." p. 40.

26 Louise Spiteri(1999) The essentialelements offace ted thesauri. p. 32.

27 RosaSan Se gun do Ma nuel (1996) Sistemasdeorganizacióndelconocimiento:laorganizacióndelconocimiento en las bibliotecas españolas. p. 106.

28 Ja klin Kornfilt y Nel son Co rrea (1993) "Con cep tual struc tu re and its re la tion to the structureof lexical en tries. p. 81 
de la Terminología. "El proceso intelectual del hablante en relación con el conocimiento sigueuna con cep tualiza ción progresiva dela realidadespecializada,ya medida que la va ad qui rien do, la con vier te en una es truc tu ra en la que cada con cep to ocupa un lugar determinado y adquiere un valor fun cio nal.La termi no logía, pues, es la basedelaes tructuradelconocimien toespecializadotemáticamente...Yloscriterios deorga ni za ción delos con cep tos quein te gran un mis mo cam po, así como su pertenencia aunde termina doconjun to, estáncondiciona dos porla for maen quelos objetos de la realidad son com prendidos porlos su jetos". ${ }^{29}$ Cada con cep to de la dis ciplina es dividido en jerarquías que implican: a) género - especie; o b) el todo y sus par tes, u otroc) tipo de re la ción tam bién je rár qui ca que Ait chi son y Gilchrist ${ }^{30}$ denominan "instance relationship", cuya traducción es denominada de diferentes formas (deejem pli ficacióno enu me ra tiva) pero que se re fie re a una es truc tu ray sus diferentescasos.

Sienla rela ciónjerárquica géne ro- es pe cie, sein cluye PERRO como categoría,en lasub secuentedivisión aparecenlas diferentes razas depe rros, como BO XER, PEKINÉS,DÁLMATA,DOVERMAN,PERDIGUERO, etcétera.Paralarelación todo-parte, a continuación de la clase VESTIMENTA, corresponde cla si ficarlas partes en las que se subdivide: BOINA, CAMISA, PANTALÓN, MEDIAS, ZAPATOS, etcétera. Porúl timo parala terce ra for ma de je rarquiza ción el siguien te ejem ploesilus tra tivo: VIAJEy los di fe ren tes tipos de via jes, VIAJETERRESTRE, VIAJEMARÍTIMO, VIAJEAÉREO.

Para un tesau ro que tiene a la edu ca ción como ma te ria dein ves tiga ción pue de ser aplicable una estructura facetada, pero, como fue ex plica dolíneas arriba,cuandola es truc tu ra que va a crearse abarcalos dife ren tes cam pos delco no cimien to que seimpar te en los progra mas de es tu dio del sis te ma edu ca tivo, és tos ya po seen una es tructuraconceptual particularquelos organiza demanerainternay sonlos modelos alos queacudenloseducadoresparacrearloscontenidoseducativos.

La razón principal para optar por los mapas conceptuales en el caso del sistema educa tivo mexica nofueque elcuerpodeconocimien tos seestructu ró en mapasconcep tuales deim parti ción dela en se ñan za, asícomo enla ne ce si dad de mantenercierta relación del tesauro con los mapas de contenidos educativos que conforman los planes de es tu dio del sis te ma de enseñan za. El agre ga dode face tas po dría ha cermás confusalautilizacióndel tesau ropara elgrupodeusuariospotencialesconstituido en sumayorpartepormaestros, productoresyestudiantes.

Sin em bargo en al gu nas dis cipli nas se agru pa ron los des crip to res con un crite rio de face tas, sólo queno apa re cen men ciona das en trepa rén te sis como se acos tumbra enlostesaurosfacetados.

A partirdela reco pila ción de términos can dida tos se comen zó ade sarrollarlaestructura conceptual del tesauro, para lo cual se partió de los mapas de contenidos

29 Teresa Ca bré (1993) La terminología: teoría, metodología, aplicaciones. p.99.

30 Jean Aitchison y Alan Gilchrist(1987) Thesaurus construction: a practical manual. p. 43. 
edu ca tivos, delos pro gra mas y te marios utiliza dos porlos maes tros de to dos los grados, ydelas moda lida des dela en señanzabásica, me dia y me dia supe rior.Los ma pas concep tuales son sub divisiones delos conjun tos de temáticas que sevan a cu briren cadamicrodisciplina, a di fe ren cia delosmapas decontenidos que cons titu yenun refle jo del nom bre de las ma te rias que no siem pre de no mi nan los do mi nios o te má ticas. La investigación para definir los descriptores del tesauro se realizó desde una perspectiva terminológica y bibliotecológica, y se obtuvo la validez de los usos lingüísticosdelapropiainformacióneducativa.

Ende finitivaelprocesodecons truc ción del tesau ro se pue de re sumiren tresetapas enlasquesedistribuyenlas actividades desarrolladasparaconcluireltrabajo:

\section{$1^{a}$.Etapa.Infraestructura}

* Selección del software para apoyar la construcción del tesauro.

* Selección del equipo humano.

* Capacitación del equipo para construir el tesauro.

* Investigación bibliográfica.

* Listado de 9.000 términos descriptores.

\section{2a.Etapa.Procesoconceptual}

* Desarrollo de los mapas conceptuales.

* Estructuración de los campos temáticos y distribución, en éstos, de los descriptores.

* Normalización de los descriptores de acuerdo con normas internacionales (ISO 2788).

* Vaciado de los datos en el software y presentación del tesauro en disco compacto.

\section{3a.Etapa.Evaluaciónypuestaenmarcha}

Revisión del balance entre campos temáticos comunes a diferentes áreas.

Desarrollo de relaciones de sinonimia y asociativas entre diferentes áreas.

PruebasenelsistemadelaVideoteca NacionalEducativaycadena de televi sión educativa (EDUSAT).

* Estudio para mejorar el software en la presentación y consulta de la información y decisión de desarrollo especial de software por el equipo de cómputo del CUIB.

\section{DESCRIPTOR Y TÉRMINO}

El término y el descriptor tienen una funcionalidad diferente en el contexto del tesau ro, sinembargo el términoeselele men to basepara es coger eldescrip tor, locualse hacemedianteeles tu diodelos significa dos queuna especialidad del conocimien to le atribuyeauncierto término.Eldescriptoryeltérminocompartenunobjetivoalbuscar la cla ridad dela co mu nica ción es pecializa daenalgún temadelámbitocul turalocientífico, pero exhiben una di fe ren ciaim portan te, porque el térmi no no se usa ais la do del 
len guajegeneral, eldes crip toren cambiore pre sen ta o significa a un documen toys e usaagrupadooasociadoconotros descriptores.

El térmi no como uni dad lin güís ti ca forma par te de un conjun to de uni da des terminológicasquereflejanlos rasgosdeunlenguajeespecializado, limitadoademás en susaspectos prag máticosysemán ticosparaotorgarlevalidezeneseámbitoespecíficodelconocimientomediantesudesincorporacióndellenguajegeneral.Sagerexplica esta dualidad de lengua je ge neral ovoca bu la rio y terminología de la siguiente manera: "Los elementos caracterizados por una referencia especial dentro de una disciplina son los términos de esa disciplina, y colectivamente forman su terminología, aquellos que funcio nan comorefe rentesgenerales den trodeunava rie dad de sublenguajessimplementesellamanpalabrasyla to talidad forma elvocabulario." 31

Lade finición de descrip torquesirviódebase para es truc turar eltesau roedu ca tivo re coge algu nos elementos dela de finición de ISO, pero al mis mo tiem po re co nocela base terminológica del descriptor y su presencia integral en el sistema de información, porqueintentanoserrestrictivoenla funcionalidaddeldescrip tor, puesésteno cum pleúnicamen te una sim ple función deín dicepararepresentarun documen toal momento de la entrada al sistema y a su salida. Por lo tanto un descriptor se define como "Untérminonormaliza doy rela ciona do den tro de un con tex to lingüís tico,en el marco de un tesau ro, que des cribey repre sen ta un de ter mi na do con te nido delos documentosparaintegrarseaunsistemadeinformación". 32

Laterminologíaparaevitarlasuperposicióndeconceptos, asícomolaflexibilidad dela len guageneral es tu dia la unidadlingüística en unámbitodeco no cimien to; "En ellenguajenaturallapolisemiaayudaalamemoriaporqueavecesunapalabrafavorece la eco no mía y la fle xibilidad del len gua jey es el con tex to el que ayu da rá a ubi car el uso de lapalabra". ${ }^{33}$ La terminología trabajabuscandocla ridady univocidad enlacomunicaciónespecializadamediantelafijacióndesignificados.

Eldes crip tor, a di fe ren cia del término, estáais lado del con tex to dellenguajepara significar un contenido representado ya sea en un texto escrito o hablado, pero al igualquelaterminología funcionadentrodeunámbitoespecializado, porlasmis mas razo nes de la bús que da de univoci dad en la co mu nica ción. El des crip tor des cribeel tema y lo representa como término preferente para indizar y recuperar la información en un sis te ma. La univo ci dad en el sis te ma de in for ma ción se lo gra me dian te el juego de la equivalencia del descriptor con no-descriptores, que son sinónimos o cuasi-sinónimosqueguíanaldescriptorotérminopreferente.

Por eso es muy importante evitar el uso de sinónimos para designar un mismo concepto en la indización o la recuperación de información. Sin embargo, la aparición de mu chos si nó ni mos para un con cep to en el tesau ro es una ga ran tía para que el

31 Juan C. Sager (1993) Cursoprácticosobreelprocesamientodelaterminología. p. 43.

32 Catalina Naumis (2000) “Análisis dela con fluen cia en tre términoy des crip tor enlaelaboraciónde tesauros" - p. 111.

33 Ángel Rai mun do Fernán dez Gon zález, Sal va dor Hervás y Vale rio Báez(1989) In tro duc ción a la se mántica. p. 90. 
usua rio acce da a la in for ma ción por me dio de tér minos que no son des crip to res. Los sinónimos apare cerán comotérminos novalida dos y re fe ridos al des crip toresco gi doparalarepresentacióndelconcepto.

Cuandosedicequeundescrip tor representaunconcepto, laconnotacióndelconcepto se estudia desde el punto de vista de su expresión a través del lenguaje. Lara opinaquelalenguaob tie ne su signi ficadodeloses que mas de cono cimien to delacomu nidad:"Lalengua es la que hace in teligibles los con cep tos que cada quien ela bo ra (tanto para el mis mo, como para los de más), pues su va li dez y su ope ra ti vi dad no se cristalizanmientras no se los con tras ta con la ex pe rien cia co mún, si nolos sig ni fica con sig nos, que los alum bran y los po nen en cues tión". ${ }^{34}$ En con se cuen cia, se gún la teoría terminológica la designación de un objeto no se da sólo a través del término, sino que cons ti tuye elins tru men to co munita rio me diante elcualse delimita el co nocimien tode algoy secon firma. La expresión "concepto" que seutilizaen este trabajo estáenmarcadaporestepensamiento.

Los concep tos pue denrepresentarenla men teno solamen te se res sino co sas yen unsen tidoamplio, cualidades, acciones, situaciones, relaciones, funciones, etcétera. Porotra partelos con cep tos nunca apa re cen ais la dos y siem pre tienen relacio nes $\mathrm{di}$ rec tas o in direc tas conotros con cep tos ein clu so com partenun cier to nú me ro deca racterísticasigualesosimilares. ${ }^{35}$

Cuan do sees tu dia un con cep to se bus caiden ti ficar los ras gos comu nes que tiene conotros conceptosy pue denabs traersealgu nos delos elementosquelocomponen paraidentificarsimilitudes. Unamesapuede estarconstruidade un materialdiferenteala maderay teneruna forma diferentealas me sas habituales redondas orectangulares, pero cuan do seoye el término mesa o seob servauna mesa, in me dia ta men te se clasificamentalmenteenlacategoríademesa.

Laestructuralingüística delos descripto resy términosincluidoseneltesau royorga niza dos en ma pas con cep tua les a partirdelas sie teáreas delaedu ca ciónmexicana convirtió la propuesta en macrotesauro, ${ }^{36}$ porque los temas presentaban confluencias enva rios ma pas ala vez y fue ne ce sa rio re vi sarla es truc tu rauna y otra vez para no repe tirlos tér mi nos y po der rela cio nar los de unárea conotra sin des man telar el apa rato sistemáticodecadaunadeellas.DiceCurrás:

[...]sella ma macro tesau ro a aquelque con tiene diferen tes te mas relacionadosentre sí, pero dis pues tosen aparta dos di fe rentes, comosise tra tase deunconglomeradodevarios tesau ros más pequeños. Un macrotesau ro está compuesto de va rios microtesau ros, que están relaciona dos en tre sí por referencias cruzadas y que abarca una amplia gama de temas, cada

34 Luis Fernando Lara (2001). Ensayosdeteoríasemántica:lenguanaturalylenguajescientíficos. p. 188.

35 Peter Weissenho fer (1995) Conceptology in terminology theory, semantics and word formation. p. 2.

36 Se hacela acla ra ción que real men te el pro duc to es un ma cro tesau ro des de el pun to de vis ta me todológico y se le otor gó ese nom bre al pro duc to fi nal, pero en la prác ti ca esta de sig nación no ha sido adop ta da en el portal dela Video te ca NacionalEdu ca tiva. Exis ten otros ca sos demacrotesaut ros como el UNBIS, que también utilizanla pala bra tesau ro. 
uno de ellos obje to de un mi cro tesau ro es pe cializado.És tos pue den desglosarse del macrotesauro y constituir un tesauro por sí mismo. ${ }^{37}$

Otro aspecto metodológico importante ha sido la utilización de las normas ISO 2788 para nor ma lizardelos re gis tros de cada tér mino. Sólouna delas reco men daciones no fue utiliza da y es la que se re fie re al uso del sin gu lar y plu ral, que aun en la traducción al español (UNE 50-106) mantiene la misma estructura sugerida para el inglés. Después de un minucioso estudio de las recomendaciones y la confrontación conprin cipios me to dológi cos dela termi no lo gía se de ci diórepresentarlos conceptos en forma singu lar;la utiliza ción del plu ralen los descrip to res sedaúnica men te en los ca sos en que és tos ten gan un sig ni fi ca do en su for ma sin gu lar y otro en su for ma plural, tal como se presenta en el UNBIS Tesauro, en su traducción al español. Un ejem plode esto es: BIBLIOGRAFÍAla ciencia, y BIBLIOGRAFÍASlosproductos.

\section{PROCESO HISTÓRICO DEL TESAURO}

Loselementosqueseutilizaron paradarleformaaltesauro fueronlos siguientes:

* CATEgorías

* DESCRIPTORES

$>$ DESCRIPTORES SIMPLES

$>$ DESCRIPTORES COMPUESTOS

* TÉRMINOS EQUIVALENTES

* NOTAS EXPLICATIVAS

* RELACIONES SEMÁNTICAS ENTRE DESCRIPTORES Y ENTRE DESCRIPTORES Y TÉRMINOS EQUIVALENTES

* TÉRMINOS RELACIONADOS.

Enlos ejercicios de cata loga ción de videos, asícomo su ce de enlaprácticaen sis temas de in for ma ción quees tán en cons truc ción, fue ron surgien do tér minos can dida tos que una vez que fue ron re visa dos yvalida dos sein corpo ra ron en laca te go ría temática correspondiente de la estructura del tesauro. Poco a poco se fue transformando el vocabulario libre en un lenguaje controlado, y se fueron estableciendo las rela ciones depertenen cia, de equivalencia, semán ticas, de jerarquía, yse redactaron lasnotas dealcance. Seen riqueció ademáscadaen tra dadeundescriptor con lasrelacionesasociativas.

Parala es truc tu ra de co no ci mien to del tesau ro se to ma ron en cuen ta los "Ma pas deContenido" elaborados paraenglobarlas ma terias del sis te ma educativo mexica node sarrolla doporlaSecretaría deEduca ción Pública,loscuales es tabanorganizados de acuer do con los pro gra mas de es tu dio e in cluían aquellas de no mina cio nes de

37 Emilia Currás. Tesauros: manual de cons truccióny uso. p. 35-36. 
las asig na tu ras de cada cam po del co no ci mien to que se im partía. No to dos los campos de la educación quedaron representados en el Mapa de Con te nidos, porlo que los ma pas de con tenido fal tan tes se de bie ron com plemen tarcon los progra mas offcialesdelasasignaturas, losplanesdeestudioylos programasdelasáreas.

Otras fuentes bibliográficas importantes corresponden a los diferentes niveles educativoscompren didosen elsis temadein forma ción que sequería representar. Se revisa ronloslibros de tex toelaboradosporlaSecretaríadeEducaciónPúblicapara la enseñanzaprimaria,ytambiénloslibros de tex to deenseñanzabásica,mediayme dia superior, y aquellos específicamente enfocados a los diversos aspectos del sistema educativomexicano. Además serealizóuna re visióndelosprogramasdeestudio,los cualessonmuyescuetos al lado delarique za quepresentanlostex tos.

Se realizaron búsquedas y acopio de la bibliografía correspondiente a obras de consulta en los diferentes campos temáticos. La es tructu racióndel tesau ro seinició con base en el méto do de duc tivo co menzan do con lain te gra ción del lis ta dode tér minos nor ma li za dos y de la lis ta he cha por ana lis tas de vi deos. Los tér mi nos de este lis ta do pre vio se agru pa ronenlos nú cleos prin ci palestemáticos a partirdeloscuales sees truc turó elesquemabásico,inicial, delmapa conceptual, paraasíestructu rarluegoelconjuntodedescriptoresysusmúltiplesrelaciones.

El pro ce sode sín te sis para arribara esta propues ta con sis tió de he cho en un acerca mien to ge neral/glo bal a la dis ciplinaen cues tión, yunavezlo gra do ésto se es tuvo encondiciones deproponereles quemabásicoy de esta ma ne rasepudo seguircon el desarrollo completo del mapa conceptualapartirdelordenamien todedes criptores conbaseensusignificado.

Sin embargo una vez estructurados los mapas conceptuales de cada uno de los principales temas, és tos tuvieronquesersometidosalacon fron tación, primerodentrodeláreaala quepertenecían,ydes puésconlas te máticasdeotrasáreas.

En esta etapa se estructuraron además las relaciones asociativas para ligar todos aquellos descrip to res quepodían manteneruna relacióndeafinidad oinclusoaveces conformarotra rela ción polijerárquicaquenoconve nía man tenercomotal,yseoptó porrelacionarlo para no perderla con no tación diferentequepresen taba, ade másde lajerárquicaenlaqueapa recíaincluido.

En apariencia la conformación de las relaciones asociativas de cada área parecía una ta rea más sen cilla de lo que en rea li dad era, ya quelain te gra ción de es tas re la ciones so me tió a re visión el con jun to de la es truc tura del tesau ro y sus relaciones termino lógi cas, locual complicó el análi sis y sus ci tó nue vas co rrec ciones queim plica ron en algunas ocasiones una nueva formulación de las estructuras jerárquicas. Por lo tantolasestructurasjurárquicas sedebieron complementarentalleres de trabajor ealizados con los especialistas de las diferentes áreas para evaluar y reestructurar los mapasconceptualeseintegrarlasrelacionesasociativas dentrodeesasestructuras.

Asi mis mo en los talle res se es tu dia ban los lis ta dos de des crip to res propues tos durante el proceso de catalogación de videos en los sistemas de información educativos participantesenelproyecto,yseevaluabanlostérminoscandidatosqueibansurgiendoe 
incorporándose al corpus terminológico.Se agregaron además innumerables notas de al can ce parade finir los térmi nos que lo re qui rie ronsiguien dola ten den cia ac tual delostesaurosde acla rarelsentidoen elquedebenusarselostérminosenelsistema.

Los resultados obtenidos son la incorporación de 20,604 términos, de los cuales 18,408 se constituyeron como descriptores. 2,167 descriptores tienen equivalentes o sinónimos enunporcentajequecorrespondeal $11.77 \%, \mathrm{y} 9,526$ mantienen relaciones je rár qui cas o aso cia tivas en tre sí; lo que quie re de cir que el $51.74 \%$ de los des crip to res estánrelacionadossemánticamenteentresí.Laestructuradecategorías estásustentada en49indicadoresdecategorías divididosenlassieteáreasyamencionadas.

\begin{tabular}{|l|c|}
\hline \multicolumn{2}{|c|}{ CIENCIAS NATURALES } \\
\hline Núm. to tal de tér minos & 6,199 \\
\hline Núm. to tal de des crip tores & 5,561 \\
\hline Núm. de indicadoresdecategoría & 4 \\
\hline Núm. de términosequivalentes & 634 \\
\hline Núm. de términosrelacionados & 2,949 \\
\hline
\end{tabular}

\begin{tabular}{|l|c|}
\hline \multicolumn{2}{|c|}{ CIENCIAS SOCIALES } \\
\hline Núm. to tal de términos & 6,192 \\
\hline Núm. to talde des crip tores & 5,383 \\
\hline Núm. deindicadoresdeca tegoría & 13 \\
\hline Núm.detérminos equivalentes & 796 \\
\hline Núm.detérminosrelacionados & 4,312 \\
\hline
\end{tabular}

\begin{tabular}{|l|c|}
\hline \multicolumn{2}{|c|}{ LENGUAJE Y COMUNICACIÓN } \\
\hline Núm. to talde términos & 2,927 \\
\hline Núm. to tal de des crip to res & 2,682 \\
\hline Núm. deindicadores decategoría & 7 \\
\hline Núm. de términos equivalen tes & 238 \\
\hline Núm.detérminos relacionados & 563 \\
\hline
\end{tabular}




\begin{tabular}{|l|c|}
\hline \multicolumn{2}{|c|}{ MATEMÁTICAS } \\
\hline Núm. to tal de térmi nos & 759 \\
\hline Núm. to tal dedes crip to res & 708 \\
\hline Núm. deindicadores decategoría & 8 \\
\hline Núm.de términos equivalentes & 43 \\
\hline Núm.detérminos relacionados & 191 \\
\hline
\end{tabular}

\begin{tabular}{|l|c|}
\hline \multicolumn{2}{|c|}{ INGENIERÍA Y TECNOLOGÍA } \\
\hline Núm. totalde términos & 1,444 \\
\hline Núm. totaldedescriptores & 1,322 \\
\hline Núm. de indicadoresdecategoría & 8 \\
\hline Núm. de términosequivalentes & 114 \\
\hline Núm. de términosrelacionados & 516 \\
\hline
\end{tabular}

\begin{tabular}{|l|c|}
\hline \multicolumn{2}{|c|}{ EXPRESIÓN ARTíSTICA } \\
\hline Núm. totalde términos & 2,677 \\
\hline Núm. totaldedescriptores & 2,409 \\
\hline Núm. de indicadoresdecategoría & 7 \\
\hline Núm. de términosequivalentes & 261 \\
\hline Núm. de términosrelacionados & 718 \\
\hline
\end{tabular}

\begin{tabular}{|l|l|}
\hline \multicolumn{2}{|c|}{ EDUCACIóN FíSICA } \\
\hline Núm. totalde términos & 406 \\
\hline Núm. totaldedescriptores & 343 \\
\hline Núm. de indicadoresdecategoría & 2 \\
\hline Núm. de términosequivalentes & 61 \\
\hline Núm. de términosrelacionados & 277 \\
\hline
\end{tabular}




\section{ANÁLISISYDISCUSIÓNDELOSRESULTADOS}

En el área de CIENCIAS SOCIALES la prime ragranca tegoría es la an tropología. Como no con tába mos con el mapa de con te ni do corres pon dien te para de fi nirsuin corporación, se partió de la idea o ámbito de acción o estudio con sideran doala antro polo gía comola cien cia del hom bre en su pro ce so de evolu ción bio lógicay cul tur ral. Pero en particular para la construcción del tesauro se consideró conveniente situarse apartirdelo que es la cul tu ray su proce so evolu tivopara asídarle se gui mientoalaevoluciónhumanaysusmúltiplesmanifestaciones.

Elnúcleocen tralpara elu cidarlos rubrosgenerales quepermitenarmarelnú cleotemáticoinicialse ránen ton ceslacul tu raysuprocesoevolutivo. Tressonasílosas pectos queseconsidera ron parade finirelconjun tode ca tego rías principales propuestas: a) el proceso evolutivodel hombreylos dife ren tes as pectos rela ciona dosconeste proceso (vis toenunaperspectiva ampliaycompleja); b) las ex presiones culturales ylas diferentes cultu ras delhombrey su pro ce so evolu tivo, yc) el cuer po teórico y sus dis tin tas ramificaciones, asícomosusinstrumentosymetodologíasdeinvestigación.

El área de ARQUEOLOGÍA se incluyó en ANTROPOLOGÍA porque en México secon sidera ala primera comoparte delas dis ciplinas an tro pológicas. En unprin cipio se pen só en in cluirla como parte dela an tro po lo gía cul tu ral, tal y comolo hace el libro de tex to que seutiliza en elColegio deBa chille res. ${ }^{38}$ No obs tan te como se suele ponercomoárea es pe cial en los es tu dios de li cen cia tu ra en an tro po lo gía, y comolicenciatura en una de las escuelas de antropología, se le asignó un lugar en el mapa conceptualcomopartedelasdisciplinasantropológicas.

Se omitió la inclusión del término ARQUEÓLOGO en arqueología porque se abrieron áreas comunes para los oficios y profesiones en las cuales aparecen todos lostérminosreferidosaestosaspectos.

Cadamapacon cep tualque se elaboró ofre cía un proble ma diferente. Por ejem plo en li te ra tu ra, que es un tema muy so co rri do en los vi deos, se optó por una vi sión gene ralque se re fleja ra en con cep tos alu si vos a la obra li te ra ria, des de el pun to de vista analítico,críticoycreativo.

Sepresen tauna selec ción delos dis tin tos tipos yva rieda des lite ra rias, quenocons tituyenuna cla si ficación delalite ra tu ra sinouna mues tra delos dis tin tos en foques literarios.Sibienestacatego rización co rrespondeaunaes truc turadefacetas, éstas no aparecenrepresentadascomotales.

Como objetivo general se trabajó siempre buscando los sinónimos de términos científicos dado el per filde usua rios del tesau ro, y seinclu ye ron aquellos como térmi nos no pre fe ren tes. En elárea deLITERATURA son fre cuen tes los térmi nos muy especializados, so bre todo en te mas como la crí ti ca y el análi sis li te ra rio, y por lo tanto tales términos debieronserutiliza dos comosinónimosnoutilizadosdelostérminos

38 Miguel Ángel Gallo (1998) Introducción a las cien ciassociales 1: bachilleres, Edi cio nes Quin to Sol, México. 
másvulgares. En elcaso de figu ras re tó ri cas sein tro du jo la cla sifica ción deés tasy, en surespec tivo sitio, sólolas figuras más importanteso aquellas quesuelenutilizarse con más fre cuen cia. El des crip torPERSONIFICACIÓN fuepreferidoaltérmino pro so popeya,porqueenlos programasylabibliogra fíano seutilizaeste término, más propio de laretóricaclásica.Decualquierformaambosaparecenreferidosenelmapa.

Elmapade con tenidode sarrollalos te mas, pero sin embargo nollega aniveles demasiado específicos. Algunos tipos de literatura se desarrollaron en forma más extensa, por ejemplo, la li te ra tu ra de quios coylali te ra tura dra mática, porque se conside ra a és tas bas tan te co no ci das y muy so co rri das en los progra mas de es tu dio. Con referenciaa otraslite ratu rascomolamexicanayla es pañola, parecenece sa rioc onside rarsus etapas y ras gos más so bre sa lien tes, ya quelas dos son amplia men te es tu diadasenelsistemaeducativomexicano.

Conrespectoaltérmino LITERATURADEQUIOSCOse se ñala que éste fue ele git dode en treotros sinónimos porqueparecemás accesible, menos peyora tivoyes pecializadoqueparaliteratura,subliteraturaoliteraturatrivial.

En el área de LENGUA Y LITERATURA se presentó otro conflicto relacionado conlas lenguas y dialec tos in díge nas. Los ana lis tas pi die ron la in clu sión de cha mu la comolengua y se tuvo que ha cerunanálisis de talla do de los 62 grupos étnicos, paralo cual se debió efectuar una consulta con el InstitutoIndigenista porque chamula no aparecía en la literatura como lengua. Se confirmó así que la lengua hablada era el TZOTZIL.

Enlalitera tu ra so bre el tema cha mula ésteapa re cía comoungrupoétnicomayense co no ci do tam bién como tzot zil que ha bi ta en la zona de los Al tos deChiapas, al no roes te del nudo de Huitepec, México, en una zona de cli ma tem pla do que en tiempo de lluvias es frío. Sus principales pueblos son: Simojovel, Mitontic, Zinacantán, Pentalhó y Chamula. Los TZOTZILES constituyen un grupo que mantiene viva su lengua y cultura tradicional, de ahí que se reconozca como término preferente TZOTZILy no Cha mula. Ende finitiva, el término Cha mula que dócomo no usa doy TZOTZILusadoporChamula.

En el área de CIENCIAS NATURALES una de las categorías en BIOLOGÍA es ZOOLOGÍA.En prin cipio se cons tru yó el mapa concep tual siguien do la ta xo no mía delaes pe cialidad, perocon pos te rio ridad se in cluye ronlas cla ses BOVINO, CAPRINO,CÉRVIDO,ÓVIDOYSUIDO, porquerepresentanunaclasificacióndemasiado específica, profunda y compleja, y su desarrollo sobrepasaría el nivel contemplado para el tesau ro. A los orga nis mos in clui dos en esas divisiones se les ubicó bajolascategorías de RUMIANTE y RUMIANTEDOMÉSTICO. En la clasificación zoológica no existen animales extintos que hayan sido incorporados en PALEONTOLOGÍA, perodebieronserrelaciona doscon ZOOLOGÍA para no perderla re fe ren cia en caso dequefueranbuscadosenlaescalazoológica.

En el área de EDUCACIÓN FISICA y EXPRESIÓN ARTÍSTICA los problemas que hubo que resolver fueron abundantes porque no existen mapas de contenidos 
edu ca tivos, nilibros de tex to, y más bien res pon den como te má ticas a progra mas de extensiónculturalqueseimpartenporlaredEdusat.

En EDUCACIÓN FÍSICA se construyeron diferentes mapas conceptuales. En primerlugarsein ten tó se guirlaes truc tu ratemáticaplantea da para el res to del tesauro,peroesto significabadividir EDUCACIÓNFÍSICA en los dife ren tes depor tes yactivida desque com prende, conlo que al aplicarle el tra ta mien to de catego rías alos deportesserepetíanlosmismos descripto rescomo PELOTA oJUEZ oÁRBITRO.

Final men te seadop tó el criteriode una obra de con sul ta ${ }^{39}$ que divide eldeporteen 13 ca te go rías, a las que se les tu vie ron que ha cer al gu nos ajus tes. En al gu nos ca sos el nombre de la categoría fue ampliado porque se encontraba expresado únicamente porun sus tan tivo que noera su ficien temen te cla ro para la orga nización de in for ma ción, y también se suprimieronal gunos deportes que difícilmen tese cono cen en Méxi co y se au men ta ron aquellos que son fre cuen tes, como:CACERÍA, CORRIDADE TOROS, PELEADEGALLOS y PESCA.Seaumen tóuna ca te go ría denominadaDEPORTEparaubicaren ella aquellos tér minos que sonco mu nes a to dos los de por teso avariosdeéstos.

Otro conflicto importante ocurrió en el área de ECONOMÍA donde el SECTOR ECONÓMICOaparecepresentadocon tres divisionesimportantes: SECTOR PRIMARIO,SECTORSECUNDARIOYSECTORTERCIARIO.Comola visióneseconómica, den tro delSECTORPRIMARIO se in clu ye a laAGRICULTURA, y en ton ces la INDUSTRIA fue integrada como parte del SECTORSECUNDARIO independientemente de laubicaciónenlaestructuradeconocimientocomopartedeláreaproductiva.

Como las CIENCIAS AGROPECUARIAS están desarrolladas desde el punto de vista productivo en el área de ingeniería y tecnología, conjuntar los dos aspectos res pe tan do la ubi cación "na tu ral" dela dis ci pli na cons ti tu yó una ta rea de mu cha coordinación. INDUSTRIAes una te má tica con la que su ce dió exac ta men telo mis mo: debióserdesarrolla da des de el pun to de vis taeconó micoen ECONOMÍA, y des de el puntodevistaproductivoen INGENIERÍAYTECNOLOGÍA.

Se incluyen aquí algunos de los ejemplos de las actividades que se fueron desarrollandoparaarmonizarlasnecesidadesqueibanpresentándoseenlaorganizacióndelos documentosaudiovisuales, conlos cambiosquesegenerabanalinteriordeltesauro.

En ANATOMÍA ANIMAL se tuvieron que desarrollar aspectos tan específicos comolaspartes delos animales que han deserin corporadas, no sóloporqueal gu nas de talespartes apa re cen en forma ais la da en al gu nos videos, sino porque ade más cons ti tuyen materiales que sirven para la construcción de artesanías, vestimenta o para la alimentación.

39 Enciclopediallustrada del Deporte. Santa Fé de Bogotá:Voluntad, 1992. 2 v. Traduc ción de: Rules of the game. Town Road,Lon don: Dia gram Visual In formation, 1990. 2v. 
Así, alin corporareltérmi no PLUMA se debe in cluir la cla se an te rior que es ALAS, y para agre gar PLUMÓNes ne ce sa rio in ter calar los ti pos de plu mas, y por lo tan to la estructuradelapluma.

Parain cluirla pa la braCONCHA seincorporólaclasean terior, ESQUELETO, y se relacionóla CONCHA con los MOLUSCOS, ya que ade más for ma par te de esta cla se y esnece sariorecordarleestoalos analis tas al mo men to delain diza cióny tambiénalos usua rios para pre sen tar no sólo la con cha como par te del es que le to ani mal sino a la vezcomounacaracterísticadelosmoluscos.

Enrelaciónconlaes tructura diges tivaseincluyóporejemploes tómago muscular, aunque éste es más conocido como MOLLEJA y también utilizado en la cocina. El término sein corporócomotalal tesauromanteniendolarela ción desinonimiaconel nombremáscientífico.

\section{RECUPERACIÓNDE INFORMACIÓN POR DESCRIPTORES}

Has ta aho rala re ferencia hasidoa la cons truc cióndel tesau ro men cionan do su relación con las siguien tes eta pas, que son las que le otor gan sen ti do: la in di za ción y la recuperación,lascualesseránexplicadasacontinuacióndemaneraespecial.

Lain dización te mática es la utiliza ción de un signoau to riza do para representaro significarunconceptodeterminado, despuésdelanálisisdecontenidodeldocumentoy, como se dijoconante rio ridad, es un ele men to más del re gis tro video gráfico.En unsis temadeinformación paramultimediaeducativasedebenincluir,ademásdelos descriptores que con forman el tesau ro, ín dices au to máticos que res catenlos términos de los resúmenes, y listados de autoridades para personajes, autores, artistas, nombresgeográficos, etcétera.

Seexplicóquetratán dosedein formación multimediaseproponelaindizacióntemática mediante un vocabulario controlado ba sa do en un mapa con cep tual, el cual permiteasignarlevarias clasesauncontenidoparaposteriormentesercombinadoen la recuperación del do cu men to en tre to dos los re gis tros de la base de da tos, lo cual otorga ma yor fle xibilidad y hace al sis te ma más sen sible para am pliarolimitar la respuestaquerequiereunusuario.

Otro elemen to de dife ren cia ción delos sis temascla si fica to rios es el niveldeprecoordinación y postcoordinación. La relación en un sistema precordinado incluye una expresión sintagmática de muchos elementos al momento de hacer la clasificación y esos mis moselemen tos de benserutiliza dos enlabúsque dapara re cupe rarlain forma ción. El sistema postcoordinado incluye elementos sintagmáticos aislados en el momentodelaindizaciónqueseconjuntanalmomentodelocalizarlainformación.

Un lenguaje postcoordinadoimplica que se podrán realizarmayorcan tidadde combina cio nes delain for ma ción al mo mentodela salida del sis te ma, al revés delo que ocurre con la utilización de una precoordinación fuerte, la cual restringe las combinaciones. 
Ejemplo:

Sistema precoordinado CONVENIOS SOBRE PRODUCTOS BÁSICOS

(En una biblio te caun libro de be rá ser bus ca do en la nu me ra ción corres pondiente de Economía)

Sistema postcoordinado CONVENIOS PRODUCTOS BÁSICOS

(La búsqueda en la base de datos permitirá que sirva para resolver una pregunta acerca de modelos de convenios o para la obtención de un listado de productos básicos o la solución de cualquier otra pregunta relacionada con cualquiera de los temas aislados o combinados entre sí o con otros)

Laindización te mática esunata rea humanaquerequiere deles table cimien todepolíticas para ob teneruna buena coheren cia dela base de da tos. Lo ideal para ope rarla es quedos personas dis tin tas leasignenlos mis mos des crip to res al mis modocu men to. El tesau roayu da a tradu cirlos con cep tos a des criptores, perola tarea dein dización deberá sercomplementada, además de que se debetenerun pro fun do co no cimien to pro fundodel tesauro,ypolíticas es tablecidas para ellopara tomarlas mismas decisiones en los casossimilares.

Sin embargo la indización por descriptores al estar fundamentada en la apreciación de los seres humanos puede presentar inconsistencias en los criterios de sistematización. El indizador es responsable de la clasificación que se haga de un documento y su nombre debe quedar registrado para llevar el control de los aciertos o errores.La revisión del contenidodeun do cu men to depen de del ba gajecul tu raldel indizador y por lo tan to tam bién dela se lec ción de con cep tos, la tra duc ción de esos conceptos en des crip to res y los en la ces sin tác ti cos en tre los des crip to res que es coja para representarosignificarelcon tenidoinforma tivoreflejaránsuconocimien to del sis te ma de in forma ción en el cual seráin ser ta do, las políticas dein diza ción y el tesauroqueusóparalaclasificacióntemática.

\section{CONSIDERACIONES FINALES}

Untesauroparadocumen tos multime diaeduca tivos seorganizapormediodelaes tructu ra lingüís tica delapropia prácticaeducativaconlacualinte ractúa el sis tema de información en el que será insertado. Los documentos multimedia educativos fijan su contenidosemán ticoporme dio dela expresiónlingüís tica para evitaruna con tex tualizacióndelaimagendiferentealaperseguidaporlosobjetivos delaenseñanza.

Eltesaurodocumentalfungecomoun sis temadeclasificación porquearticulalos temas delosvideospara recuperarlainformaciónquecontienen.

Los videos, como cual quier otro do cu men to de ar chi vo, tie nen un or den de procedencia o entrada al sistema, pero los temas y otros elementos de autoridades son losquepermitensuposteriorrecuperación. 
Laconstruccióndeuntesaurodocumentalimplicaunconocimientopro fundode los te mas in clui dos enél y de las re la cio nes de sus tér mi nos y des crip to res, así como deldesarrollodelasespecialidadessegúnlaprácticadecadapaís.

Laes truc tu ra del tesau ro do cu men tal debe llevarse a cabo en el mis moidioma del sistemadein formación, porquecadaidio mallevaimplícitounen foque culturaldiferente. Esto no quiere decir que no se puedan desarrollar equivalencias idiomáticas, perola cons truc ciónes más ade cua da, consis ten te ein teractúa en forma máseficiente con el sis te ma de in for ma ción, cuan do se ela bo ra en elidio ma de los do cu men tos quesevanarepresentar.

Elmodelode tesau ro subyacen te en este trabajo de in vestiga ciónpodráseradoptado para otros tesauros similares, pero el producto obtenido diferirá de un país a otroencontenidoscurricularesyexpresionesidiomáticas.

Lainves tiga ción teó ricay prác tica para la modeliza ción de un tesau rodebe aglu tinarungru po de es pe cia lis tas que con flu yan para ha cer el diseñoes truc tu ral dela herramienta, asícomoparade sarrollarlos términosnormaliza dos delas dis ciplinasimplicadasen elsistemaeducativoquesevaarepresentar.

Un tesau ro es un sis te ma que re quie re ser re visa do con perio di cidad por un equipodeman tenimien to, además de serevalua do en forma permanen te porlos usua rios dela base de da tos en que sein serta, y debe serel re sul tado dela con tribu ción de unos y otros bajo esquemas de colaboración claros y como parte de un proyecto amplio encaminado a mejorar el conocimiento del sistema de información. Los tesauros sólosepublicanenpapelcuando sustentansistemasdein formaciónpequeñosymuy es pe cia li za dos; para pro ce sos más am plios y de tipo ge ne ral como el caso que se presentaen estetrabajo, sede sarrollany man tienen in te gra dos en for ma to electrónico, que sería como la espina dorsal del sistema de información y que tendría que estar apoyadaporunaactualizaciónperiódicaadecuadaaltema.

Elcomportamientodela he rramientageneradaapartirdelpresenteestu diodebe seguir sien do analiza do enla co mu nica ción ac tiva en tre el sistemade in formación y losusuarios finales, elcosto-beneficiodesumantenimien toyla actualizaciónye liminación de la ambigüedad, vaguedad y desuso que puedan presentar sus términos y descriptores.

\section{OBRAS CONSULTADAS}

AITCHISON, Jean y Alan Gilchrist. Thesaurusconstruction:apracticalmanual. - 2nd ed. London: ASLIB, 1987. - 173 p.

AUMONT, Jacques. La imagen / traducción de Antonio López Ruiz. Barcelona: Paidós, 1992. - 336 p. - (Paidós Comunicación; 48) 
BARITEROQUETA, Ma rio Guido. "La no ción de ca te go ría y sus im plicaciones en la cons truc cióny evalua ción delenguajes documentales.”-p. 39-45. - En CONGRESO ISKO-ESPAÑA, EOCONSID 99 ( $4^{\circ} .: 22-24$ abril, Granada) Representación y organización del conocimiento en sus distintas perspectivas:suinfluenciaen la recuperación de lainformación.-Gra na da: Ca pí tuloEs pañoldeISKO.FacultaddeBiblioteconomíayDocumentación de la Universidad de Granada, 1999.

BORDWELL, David. Narration in the fiction film. - Madison, Wisconsin: Univ. of Wisconsin, 1995.

BURKE, Mary A. Organization of multimedia resources: principles and practice of information retrieval. - Aldershot: Gower, 1999. - xii, 224 p.

CABRÉ, María Teresa. La Terminología: teoría, metodología, aplicaciones / traduc. de Carles Tebé, prólogo deJ.C.Sager.-Barcelona:Ed. An tár ti da, 1993. -529 p.

CABRÉ,María Teresa. “Terminologíay do cu men ta ción”.-p.231-247.En su Laterminología: representación y comunicación:elemen tosparaunateoría de base comunicativa y otros artículos. - Barcelona: IULA, 1999.

CHAUMIER, J. Análisisylenguajes documentales:eltratamien to lingüístico delain formación documental. - Barcelona : Mitre, 1986. - 173 p.

CURRÁS, Emilia. Tesauros: manual de construcción y uso. Madrid: Kaher II, 1998. - 209 p.

"Documentación-Directrices para el establecimiento y desarrollo de tesauros monolingües.PNE - 50 160. ISO-2788-1986. (Parte I)." - p. 263-483. - En Revista Española de Documentación Cientifica - Vol. 12, no 4 (1989).

"Documentación-Directrices para el establecimiento y desarrollo de tesauros monolingües. PNE-50106.ISO-2788-1986 (E). (Par te II)." - p. 601-629. - En Revista Española de Documentación Científica. - Vol. 13, n ${ }^{\circ}$ $1(1990)$

ESPÍRITUREYES, Sara e Ire ne MartínezZa ran do na. "La edu ca ción a distancia y el Sistema Edusat, una alternativa pedagógica para el siglo XXI". - p. 39- 48. - En Usopedagógico delatelevisión/ coordinadoraIrene Martínez Zarandona. - México D.F.: Instituto Latinoamericano de la Comunicación Educativa, 1999. - 179 p.

FERNÁNDEZ GONZÁLEZ, An gel Raymun do, Salva dor Her vás y Valerio Báez. Introducción a la semántica. - 5ª ed. - Madrid: Cátedra, 1989. 251 p. (Lingüística)

FERRÉS, Joan. Videoyeducación.-Barcelo na: Paidós,1988,1997.-213p.

GIL URDICIAIN, Blanca. Manual de lenguajes documentales. - Madrid : Ed. Noesis, 1996. - 269 p. 
GUINCHAT, Claire y Michel Menou. Introduccióngeneral a las cien ciasy técnicas de lainformacióny documentación. $-2^{\mathrm{a}}$ ed. co rreg. y aum. / Ma rie Fran ce Blanquet. - Madrid: UNESCO, 1990. - 555 p.: il

"Hitosyan tece den tes dela televisión edu ca tivay cul tu raldeMéxico".-p. 9. - En Edusat guía de programación / Secretaría de Educación Pública, editadaporelIns titu toLatinoamerica nodelaComunicaciónEducati va y la Dirección General de Televisión Edu ca tiva. - Año 7, 2a épo ca, no. 38

IGLESIAS MATURANA, María Texia. Análisis y recuperación de información documental.-Santiagode Chile: Ediciones Ins titu to Pro fe sionaldeSantiago, 1992. - xv, 237 p.

KORNFILT, Ja klin y Nel son C ORREA. "Conceptual struc tu re and its rela tion to the struc tu re of le xi cal en tries." - p. 79-118.-EnKnowledge and language / edited by Eric Reuland and Werner Abraham. - Dordrecht: Kluwer, 1993. - Vol 2: Lexical and conceptual structure.

LANCASTER, F. W. Elcontroldelvocabularioen larecuperación deinformación / traducción de Ale jan dro de la Cue va Mar tín. - $2^{\mathrm{a}}$ ed. - Sa ra gos sa: Universitat de Valencia, 2002. - 286 p. - (Educació. Materials; 12)

- - Thesaurusconstruction anduse a con den sedcourse - Pa rís :UNESCO, 1985. 89 p. - (PGI-85/WS/11)

LARA, Luis Fernando. Ensayos de teoría semántica: lengua natural y lenguajes cientificos. - México: El Colegio de México, 2001. - 261 p. - Jornadas; 135)

Macrotesauro Mexicano para Contenidos Educativos / Coordinadora general y edito ra Catalina Naumis Peña.-En funcionamien to en el Sis temaIn tegraldelaVideotecaNacionalEducativayelIns titutoLatinoamericano de la Comunicación Educativa - Publicado en páginas electrónicas http://cuib.laborales.unam.mx/ tesauro/ y http://168.255.172.1/ (Documento interno en papel y en disco compacto) (Depósito legal 03-2003-022714345800-01)

(Contiene 20,604 términos del corpus alfabético, Índice permutado, Índicesjerárquicos, Listadodeidentificadorescontroladosdepersonajes e instituciones).

MOLHOLT, Pat y Toni Petersen. "The role of the 'Art and Architecture Thesaurus' in communicating about visual art”. - p. 30-34 - En Knowledge Organization. - Vol. 20, no. 1 (1993).

NAUMIS PEÑA, Ca talina. "Análisis delaconfluencia en tre términoydescrip tor en la ela bo ra ción de tesau ros". - p. 95-113. - EnInvestigaciónBibliotecológica: archivonomía, blbliotecología e información. - Vol. 14, no. 29, julio/diciembre de 2000. 
NAUMIS PEÑA, Catalina. "Dinámica en la cons truc ción de tesau ros y el ac ce so a la in for ma ción”. - p. 69-90.-En La infor ma ción en el ini cio de la era electrónica: organización del conocimientoy sistemas de información/ Cen tro Universitario de Investigaciones Bibliotecológicas. México D.F.: UNAM, El Centro, 1998. - Vol 1. (Monografías; 25)

--. "Ima ges and words".-p. 120-126.-En In terna tio nal con fe ren ce of the international society knowledge organization: "challenges in knowledge representation and organization for the $21^{\text {st }}$ century: integra tion of knowledge across boun da ries ( $7^{\mathrm{a}}$ : July 10-13,2002: Gra na da, España) (Advances in knowledge organization; 8) ISSN 0938-5495

- -. "Indización y clasificación: un problema conceptual y terminológico”. - En Documentación de las Ciencias de la Información. - No. 26, 2003. (En prensa)

NAUMIS PEÑA, Ca talinay Ma ría Texia Iglesias Ma tu rana. "Unlenguaje paralaorganizacióndelconocimientobibliotecológicoen AméricaLa tina." - p. 81-86. - EnCONGRESOISKO-ESPAÑA,EOCONSID 99 ( $4^{\circ} .: 22-24$ abril, Gra na da) Representaciónyorganización delconocimientoensus distintasperspectivas:suinfluenciaen la recuperación de lainformación. - Gra nada: Capítulo Español de ISKO. Facultad de Biblioteconomía y Documentación de la Universidad de Granada, 1999.

Normas, prácticas recomen da dasyestrategiasIASA-TC 03. La salvaguarda del patrimonio sonoro: ética, prin cipiosy es tra te gias depre servación (ver sión del 2 de septiembre de 2001) / Traducción de Fernando Oso rio Alarcón.-México: Radio Educación, 2003. - 16 p.

PANOFSKY, Erwin. "Iconografía e iconología: introducción al estudio del arte del Re na ci mien to".- - p. 37- 59.-EnElsignifica do en las Artes Vi suales. - Buenos Aires: Ed. Infinito, 1970.

RANGANATHAN, S. R. Elements of Library Classification. - Bombay: Asia Publishing House, 1962.

RENDÓN ROJAS, Miguel Ángel. Basesteóricasyfilosóficas de labibliotecología. -México: UNAM. Cen troUniversitariodeInves tigaciones Bibliotecólogicas, 1997. - xi, 132 p. (Monografías; 24)

RODRÍGUEZBRAVO, Án gel (1998)Ladimen sión sonoradellenguajeaudiovi sual. Barcelona: Paidós, 1998. - 270 p.

SAGER, Juan C. Curso práctico sobre elprocesamien to de la terminología/con un capítulo adicional de Joan Toruella y Gloria Clavería; bibliografía de Blaise Nkwenti-Azeh; traducción del inglés Laura Chumillas Moya. Madrid: Fundación Guzmán Sánchez Ruipérez, 1993. 448 p.- (Biblioteca del libro; 57)

SAN SEGUNDO MANUEL, Rosa Sistemasdeorganizacióndelconocimiento:la organizacióndelconocimientoen lasbibliotecasespañolas. Madrid:Universidad Carlos III en Madrid, 1996. - 317 p. - (Col. Monografías; 15) 
SLYPE, Geor ges Van. Loslenguajes de in dización:con cepción, construcciónyutilit zaciónen lossistemas documentales. - Ma drid:Fun da ción Ger mán Sán chez Ruipérez, 1991. - 200 p.

SPITERI,Loui se. "The essen tial ele ments of fa ce ted thesau ri".-p. 31-51. - En Cataloging \& Classification Quarterly. - Vol. 28, no.4 (1999).

TIFFIN, JohnyLalita Raja singham. En bus ca de la cla se virtual: la edu cación en lasociedaddelainformación / prólogo de GabrielFerra téPas cual.-Barcelona: Paidós, 1997. - 274 p. - (Temas de educación; 43)

THOMAS, Alan R. "Termi nological problems: ocu rrence, cau ses, con sequen ces and solu tions in guidan ce, coun selling and asso cia ted fields".p. 40-52. - En International Journal of Information and Library Research. Vol. 1, no. 1 (1989)

UNBIS TEsauro: listatrilingüe detérminos usa dos comoen ca be zamien tos de materias en el análisis de documen tosypublicaciones re laciona das con losprogramasyactioidades de las Naciones Unidas.-Nueva York: Na ciones Unidas, Biblio teca Dag Hammarskjöld, 1986. - 571p

VALDIVIA DOUNCE, Lourdes Palabrasycosas: unasemán ticacognitivadelos términos singulares. - México DF: UNAM. Coordinación de Humanidades. Centro de Neurobiología, 1998. - 306 p.

VIZCAYA ALONSO, Dolores Información:procesamientodecontenido.-Ro sario: Parhadigma, 1997. - $187 \mathrm{p}$

WEISSENHOFER, Peter. Conceptology in terminology theory, semantics and word-formation: amorpho-conceptually based approach to classification as exempli fiedby the Englishbaseballterminology. -Vien na: In ter na tio nal Network for Terminology, 1995. - xi, 270 p. - (IITF series; 6) 